\title{
Learning and digital inclusion: the ELAMP project
}

\author{
Kate D'Arcy*
}

The Department for Applied Social Studies, The University of Bedfordshire, Bedfordshire, UK

(Received 21 April 2012; final version received 2 November 2012)

The Electronic Learning and Mobility Project (ELAMP) was a nationally funded project by the Department for Children, Schools and Families, which ran from 2004 to 2010. The main aim of ELAMP was to improve the education of Traveller children, particularly highly mobile learners. ELAMP focussed upon the use of mobile technology and distance learning to support, enhance and extend young Travellers' educational and vocational opportunities. This article will reflect upon the learning and technological experiences and opportunities that the ELAMP project provided for Traveller children, young people and their families. In doing so it will critically consider the value of information technology in working with Traveller communities and advancing their educational opportunities. Reviewing ELAMP work will also demonstrate how the use of mobile technology can improve educational outcomes and Traveller families' digital inclusion. Now that the project has ended, this article will question why we are not using what we learnt from ELAMP to move forward. The author was a tutor on the project who also evaluated the Strand B, Wider Key Skills element of ELAMP for The University of Sheffield between 2008 and 2010, which is the main focus of this particular article.

Keywords: ELAMP; education: digital inclusion; information technology; young Travellers and their families

\section{Introduction}

\section{Purpose}

The purpose of this article is to disseminate good practice and critically consider how lessons learnt from ELAMP can be absorbed and adopted into both current and future digital learning strategies. When presenting case studies of good practice, Casacuberta (2007) suggests one should document the purpose, problem, solution, target, actors, effects and implementation - all of these aspects will be covered within this article in consecutive order. The final section highlights the challenges for ELAMP \& Digital Inclusion and raises critical questions about future learning and digital developments as cuts to funding across services suggest that although ELAMP enabled some Traveller families' digital inclusion, many are still not included or have become excluded once more. This article begins with a brief explanation of its terminology regarding Travellers.

\footnotetext{
*Corresponding author. Email: lemmie9@hotmail.com

RLT 2012. (C) 2012 K. D’Arcy. Research in Learning Technology is the journal of the Association for Learning Technology (ALT), a UK-based professional and scholarly society and membership organisation. ALT is registered charity number 1063519. http://www.alt.ac.uk/. This is an Open Access article distributed under the terms of the Creative Commons "Attribution 3.0 Unported (CC BY 3.0)" license (http://creativecommons.org/licenses/by/3.0/) permitting use, reuse, distribution and transmission, and reproduction in any medium, provided the original work is properly cited. 


\section{K. D'Arcy}

\section{Terminology}

The term 'Traveller' is a generally accepted one and refers to several groups who were historically and may still be nomadic. The term includes a range of identifiable groups including Roma, English Gypsies, Irish/Scottish/Welsh Travellers, Circus people, Showmen and New Age Travellers. Gypsies, Scottish and Irish Travellers are recognised ethnic minorities and are protected under the Race Relations Act (1976) (as amended by the Race Relations Amendment Act 2000).

Other groups, such as Showmen are not recognised officially as ethnic minorities, nevertheless all groups experience discrimination (Willers 2012). Defining who is called a Gypsy or Traveller is a personal matter of ethnicity and self-ascription and certainly does not exclude those who live in houses or whom no longer travel. This article will refer mainly to Gypsy/Roma, Irish Travellers and Showmen families, as these communities were all participants of ELAMP.

\section{The problem: Travellers, education and ICT}

There is a wide range of literature on the education of Traveller children and the difficulties they continue to experience in mainstream education (Derrington and Kendal 2004; Jordan 2001; Wilkin, Derrington, and Foster 2009). These difficulties in school have historically centred on access and inclusion. During the 1960-70s, many Traveller children did not access education due to the fact that families led very mobile lives. Today, many Travellers are more settled, yet they continue to experience barriers to their education. The Office for Standards in Education (OFSTED 2003) described Traveller children as the group most vulnerable in the education system and the one minority group who are too often out of sight and mind (p. 21).

Since 2004, Gypsy/Roma and Travellers of Irish heritage have been included in the Pupil Level Annual School Census (PLASC); consequently, there is statistical data that determines that Traveller pupils from these groupings consistently achieve the lowest attainment scores of all minority ethnic groups in England. Indeed the Equality and Human Rights Commission (2010) suggested that the attainment gap is not reducing but widening for these groups. Showmen and Fairground pupils experience similar difficulties in schools as Gypsy/Roma and Travellers of Irish Heritage, yet the fact that they are not recognised as ethnic minority groups means that such data is not available.

Research has shown that some children's achievement in school is linked to the fact that they cannot attend one school regularly (Jordan 2001). Travellers, young carers, 'looked-after' children, refugees, children with chronic illnesses and homeless families all share discontinuity in their learning, and as a consequence, they often underachieve (Jordan 2001). Although some educational difficulties are associated with mobility, it is important to note that mobility is not the main barrier to Traveller children's achievement and inclusion in school. The most prominent issues concern racism and bullying, negative teacher attitudes and inconsistent or inadequate levels of support (Lloyd and McClusky 2008; Wilkin et al. 2010). Traveller pupils have disproportionally high school exclusion rates and low attendance levels that affect their retention, particularly at secondary school level. Moreover, disproportionate levels of Traveller children are inappropriately identified as having Special Educational Needs (Wilkin, Derrington, and Foster 2009). 
The law acknowledges that some Traveller families are engaged in a trade or business that requires them to travel from place to place and that this can affect school attendance. The law states that 'each child must attend school as regularly as that trade or business permits, and children over 6 years of age must attend at least 200 sessions in each rolling 12-month period' (DCSF 2008, p. 8). When schools are informed by Traveller families that they are travelling as part of their family trade, they can mark them with a $\mathrm{T}$ in the register, which is counted as an authorised absence.

Highly mobile Traveller families, such as Showmen, are typically on the road from late February until November every year and are only present at their winter-base school for relatively short periods of time; however, they may attend other schools during their travels. Children tend to be registered at their base school.

A 'base school' is the school that a child from a Gypsy, Roma or Traveller family most recently attended during the preceding 18 months, when the family was not travelling.

The legislation calls it the 'school of ordinary attendance'. (DCSF 2008, p. 2)

Historically, highly mobile Traveller children relied on paper-based work packs which were provided by their winter-base schools to continue their learning whilst travelling. A survey of all English Traveller Education Services (TES) found that around 1300 Traveller pupils were taking some form of learning pack with them whilst travelling (Marks 2005). Children are often reliant upon parental support to complete work packs on the road. Nevertheless, if they attend other schools during their travels, teachers in these schools can mark work packs and give children new work. Where Traveller families do not stop for long enough to go to school, the TES could traditionally be called upon to come out to children to review progress and provide new work.

TES originated out of the need to address the historic difficulties Traveller children experience in accessing and achieving in education. TES started up in the 1970 s, yet their work only really developed in the 1990s through the provision of centralised funding (Derrington and Kendal 2004). Up until 2010, TES provided a well-integrated national network, which could support mobile families and provide continuity of provision for pupils as they moved from one Local Authority (LA) area to another. However, recent government spending cuts have seriously affected the support that TES can provide (Doherty 2011).

The ELAMP project was also set up to address the difficulties Travellers experience in school through the use of information technology and it relied on TES support to do so. The next section will provide a brief contextual overview of ELAMP work. Because the outcomes of ELAMP are well documented within other reports, ${ }^{1}$ this article will critically analyse just one aspect of the project (Strand B) and its value in advancing Travellers' educational and IT opportunities.

\section{The solution: the Electronic Learning and Mobility Project}

ELAMP was not the first project to use IT to develop inclusive approaches for Traveller education - it drew on European research projects in the 1990s with mobile Traveller families. These earlier projects were funded by the European Commission and led by the European Federation for the Education of Travelling Communities (EFECOT) who co-operated with various organisations in a European Network. The work of EFECOT started the exploration into the use of wireless technology to 


\section{K. D'Arcy}

support educational provisions to the particular needs of the Occupational Travellers in Europe and England. Occupational Travellers are defined by the European Parliament as the Bargee, Circus and Fairground communities across Europe, seasonal workers, and others who travel as a direct consequence of their trade or profession (Marks 2003).

Occupational Traveller pupils often face of a lack of learning continuity. Topilot ${ }^{2}$ used multimedia technologies to enhance distance learning and improve education of the circus, fairground and bargee children. Teachers in 15 schools from four European Union member states were trained to use IT in their daily teaching methods in order to experience how IT could help them and their parents when they were not present in school.

The Flex project followed Topilot. It combined multimedia and traditional learning methods to improve the learning of travelling pupils. A computer-based learning environment allowed teachers to monitor and manage the learning process at a distance, motivate the learner and provide a relevant, flexible learning path for each learner. Trapeze took a step further by using satellite-based technology to link children and teachers in the Netherlands and the UK in a 'virtual' learning environment.

EFECOT saw the value in using technology to prevent Traveller pupils and their families from dropping out of education. They also emphasised the value of IT in reducing Travellers' social exclusion. Traveller communities were considered to need additional support, to prevent them from being left behind.

ELAMP continued under this agenda. ELAMP began in 2003 with a yearlong research exercise coordinated by the National Association of Traveller Teachers (NATT), which was funded by the Nuffield Foundation. The aim was to explore ways of using IT to enhance and support distance learning for highly mobile Traveller pupils. The initial pilot concentrated on Internet use with a small number of highly mobile Traveller families to facilitate contact with their winter-base school and to improve children's learning progression. It found that IT could have a significant impact on the learning and confidence of Traveller pupils:

It has been staggering just how much the pupil's confidence has increased. They are much more motivated to write and record ideas generally and have made the transition back to school better than ever (Anonymous quote in Marks 2005).

As a result, a series of projects followed which developed ELAMP year-on-year. Each project lasted for one academic year and was numbered sequentially ELAMP 2, ELAMP 3 and so on. The final project in 2009-2010 was referred to as ELAMP 7.

Families who took part in ELAMP were loaned a laptop, a printer and mobile Internet to take with them whilst they were travelling. ELAMP 2 involved just 20 primary-aged distance learners yet by 2008-09, the project was supporting 122 primary-age pupils and 140 secondary-aged students. By 2009 there were over 500 learners plus siblings and parents benefitting from ELAMP (Marks 2010).

ELAMP was divided into different strands. Strand A concerned the use of IT to improve learning continuity and progression for Traveller pupils in schools by facilitating partnerships between parents, schools and TES to maintain learning continuity. Strand B took on a further challenge that relied on additional support from the TES to address the concerns regarding disengaged secondary-aged Travellers. This element of ELAMP began in 2006 and is the focus of this article. 
Although ELAMP started with a focus on supporting highly mobile distance learners, from 2008 ELAMP included Traveller pupils who did not travel away from school. This decision was made on the basis that many Traveller families have limited access to IT and connectivity. The project chose to provide digital learning opportunities for less mobile Travellers as it was felt that they would benefit from having a laptop and Internet access in their homes also. Indeed, it was hoped that by including these families digitally would improve children's engagement with formal education. This decision was politically encouraged in the run up to the Home Access $^{3}$ programme and this topic will be returned to later on.

\section{The target: disengaged and disaffected learners}

Research has shown that although Travellers' attendance and attainment in primary school has increased, there are still serious concerns surrounding secondary-aged Traveller students (Derrington and Kendal 2004; Wilkin et al. 2010). Wilkin et al. (2010) found that only one in five Traveller students completed secondary school nationally. Strand B was set up for secondary age Travellers to address their high disengagement and dropout rate at school. This Strand B element was also referred to as 'Wider Key Skills' because it developed a specific Wider Key Skills on-line learning programme for Traveller participants in Years 9, 10 and 11, or Key Stage 4. ELAMP Strand B was specifically developed to meet the vocational and personal interests of young Travellers. The aim was to re-engage students through relevant, accessible on-line learning materials and provide an opportunity to gain much needed qualifications.

Learners were provided with a laptop and Internet connectivity, which by this time was provided via the use of a dongle. ${ }^{4}$ The ELAMP Wider Key Skills programme referred to young Traveller participants' as 'members' to reflect the early adult status, which the $14+$ age group has within Traveller communities (D'Arcy and Marks 2008). Teacher and tutor support was provided by TES staff, referred to as 'advisors'.

The programme involved a series of challenges, some of which were specifically targeted at the vocational interests of young Travellers, and allowed them to gain recognised Wider Key Skill qualifications, accredited by ASDAN. At this point in time, Wider Key Skills were skills considered to be commonly required for success in a range of activities in education and training, work and life in general (Asdan 2011). The ELAMP Wider Key Skills programme covered the three main key skills: Working with Others, Improving Own Learning and Performance and Problem Solving.

Learners could choose from a variety of challenges including 'Looking after an Animal', 'Hair and Beauty', 'Pricing a Job' and 'Discovering my Family History'. The minimum academic requirement for participation on the programme was a reading age of 8 years. Learners needed to complete two challenges for each Wider Key Skill and six challenges in total, to gain the equivalent of two GCSEs. Learners could complete units at Level 1 or 2. Level 1 equates to GCSE grade D-G, and Level 2 GSCE grade $A^{*}$ to $C$. The majority of learners worked at Level 1 . With dedicated support learners could achieve two-three Wider Key Skills in one academic year. The Strand B pilot began in 2006 with 20 young Travellers across their four LA-based TES. By 2007, there were 61 active learners across 14 TES. In 2008, there were approximately 100 young participants supported by 20 TES. 


\section{K. D'Arcy}

Strand B was essentially alternative on-line educational provision delivered by TES staff, although as the project developed other agencies including Connexions and school staff were trained as tutors as many TES were trying to deliver the programme on top of already full timetables. Hence, in the final year additional funding was sought to secure advisor support - approximately 1 day for five pupils as previous experience indicated that learners all required face-to-face support alongside on-line provision. A small number of TES partners could apply to deliver the final funded pilot year which involved just 12 of the 21 original TES partners. The next section will consider the actors (learners) involved in the last year of ELAMP Strand B in order to highlight the role blended learning in the form of mobile technologies and tutor support can play in improving educational inclusion.

\section{The actors}

The final year of ELAMP Strand B had a cohort of 50 young Travellers. The grid below indicates the educational provision and school year group of those involved.

\begin{tabular}{lcrccc}
\hline & Y9 & Y10 & Y11 & Other & Totals \\
\hline School & 1 & 5 & 2 & & 8 \\
PRU & 1 & 0 & 2 & & 3 \\
EHE & 7 & 11 & 8 & & 26 \\
Non-EHE & 5 & 5 & 1 & & 11 \\
Other & & & & 2 yr. 12 & 2 \\
Totals & & & & & 50 \\
\hline
\end{tabular}

The largest cohort was home educated. The project observed that although many pupils had attended primary school, they withdrew at secondary stage to be home educated. The highest school-leaving rate was in Year 6, followed by Year 8, Year 9 and then Year 7. As the table below indicates, roughly $50 \%$ of these disengaged learners had left school at the end of primary school.

When pupils had left school - 2009/2010

\begin{tabular}{lrrrrrrr}
\hline Year group & 4 & 5 & 6 & 7 & 8 & 9 & 10 \\
No. of students & 1 & 1 & 16 & 6 & 7 & 6 & 1 \\
\hline
\end{tabular}

Because many learners in Strand B had missed out on schooling having only completed primary level education, they often required additional support to engage and progress with on-line materials.

Within educational discourse there is an assumption that school is best and necessary for children's development (Monk 2004). Nevertheless, there is significant data to suggest this is not the case for marginalised groups and those who are not interested or motivated by purely academic learning opportunities (Bernstein 1974; Gewitz and Cribb 2009; Raey 2010). ELAMP evaluation data suggested that Traveller pupils had left mainstream schooling because of fears about treatment in school such as bullying and discrimination. Several students also remarked that they did not enjoy school and felt continuing in school did not fit with Traveller culture or suit their individual needs. 
Nevertheless, Traveller children, young people and their families were still committed to learning and IT provided a way to continue educational progression. Thus, ELAMP facilitated a different way to continue learning and education. To provide an insight into the ELAMP experience, Chanel's ${ }^{5}$ story is included below. Chanel was in Year 11 at the time of ELAMP.

Chanel comes from a large family with five brothers. She attended primary but left after two weeks in Year 6. She did not go on to secondary school because she was not offered a place at the local school; the school that had a place was further away and had a bad reputation. Chanel had never used a laptop before she started ELAMP. She needed a lot of initial support with basic IT skills and getting back into a routine of learning. Her tutor, a Connexions worker employed within a TES, was able to provide initial and ongoing support to complete her ELAMP work.

Chanel met regularly with four other girls on ELAMP in a youth centre where they were supported by her tutor and another member of the TES staff. Chanel's progress went beyond any expectations and she completed all six ELAMP challenges. Chanel also completed a Level 1 BTEC in Health \& Social care at a local Education Youth Service. The combination of both learning programmes provided her with the necessary learning experiences to apply to College. At the time of interview Chanel was about to be interviewed for a Child Care course in the following academic year. Her tutor also helped her organise a work placement in a local nursery setting.

These learning experiences allowed her to mix with a wide range of other young people and professionals; Chanel found staff supportive and made many new friends. Her progress was amazing. She clearly loved learning and quickly mastered IT skills, reading and writing skills also improved enormously. These skills are vital to her own learning progression but also help her family as she has been able to teach her younger brother how to do Power Point presentations and helped him with his homework. Her own self-confidence and esteem has also improved significantly. Her tutor is very proud "You never have to sit behind Chanel, she just does it!"

Delivery of ELAMP Strand B was flexible and varied across TES teams. Some teams delivered ELAMP for a group of learners, who like Chanel, met regularly and completed work together. Other TES delivered ELAMP on a one-to-one basis, often in the home of Traveller learners, a decision often driven by geographical practicalities, where students lived too far away from each other to facilitate group meetings. Whatever approach was used, the essential element was regular tutor input to maintain motivation and momentum towards reaching agreed goals. Interviews with families regarding ELAMP Strand B confirmed that relationships between families and tutors were very important. Families said that they liked the flexibility of ELAMP as it facilitated children's learning because they were happy and they were enjoying the work:

One mother explained that when her children got back from their ELAMP session they got straight on with 'homework' tasks without being asked. In school she said they did not do their homework and did not learn because they were so unhappy. (Anonymous quote 2009) ${ }^{6}$

\section{The effects}

Out of the cohort of 50 in the final year, 59\% achieved at least two Wider Key Skills and $31 \%$ achieved one Wider Key Skill qualification by summer 2010 when the project ended. There were a number who missed the deadline and planned to submit work later, which would have taken the total achieving two qualifications up to $66 \%$. 


\section{K. D’Arcy}

These are qualitative outcomes, yet they do not capture the quantitative benefits many learners experienced. These effects are harder to evidence and include higher levels of self-esteem and more focussed aspirations with plans for college, training courses or work, which had been vague if non-existent at the beginning of ELAMP.

Traveller communities have long been identified as groups who are less well served and would benefit from innovative uses of IT (Jordan 2001; Digital Inclusion Team 2007). ELAMP was a unique example of a UK digital learning project that received several years of funding to improve the educational experiences for young Travellers and their families. ELAMP drew on technological advances and developed previous European IT initiatives to enhance Travellers' learning experiences. ELAMP showed that enabling Travellers to be recipients of IT-led educational programmes is important and can address poor academic achievement in school. In regards to digital inclusion ELAMP enabled Traveller children and their families to have a more equal distribution of resources.

The evaluation of ELAMP indicated that Traveller communities should be the recipients of innovative educational uses of IT for two reasons. First, IT transformed the concept of education. By providing accessible, flexible, relevant and alternative educational provision, ELAMP enabled learners, families and teachers to access positive learning experiences even when young Travellers had disengaged from mainstream school. ELAMP gave young Travellers another chance and allowed them to access post-16 provision if they wanted to, despite not completing secondary school. The qualifications they achieved as part of ELAMP were therefore an important part of their learning continuity.

Second, ELAMP enabled Travellers' digital inclusion. Although the main focus of ELAMP was to use IT to improve the learning experiences of Traveller children and their families, provision of equipment and on-going IT support also addressed the digital divide. Although there is very limited data on the number of Traveller families who have computer and Internet access in their homes, professional experience suggests this figure it much lower than within the settled, non-Traveller community. Van Dijk (2006) suggests that this equal distribution of resources is an important objective in addressing the digital divide and wider inequalities. The work of EFECOT and ELAMP emphasised the value of IT in reducing Travellers' social exclusion. Indeed they highlighted that Traveller communities should be the focus of on-going digital inclusion in an educational context because of their marginalised, socially excluded position in society and education, a discussion which the next section expands on.

\section{Implementation: the digital divide and social exclusion}

The digital divide can be described as 'the gap between those who do and do not have access to computers and the Internet' (Van Dijk 2006, p. 178). Although the importance and relevance of the digital divide is contested (Strover 2003) most will agree that IT has become increasingly important aspect of effective participation in 21 st century society (FutureLab 2007). Yet, Van Dijk highlights that a significant obstacle in the research and discussion regarding inequality of IT access is the multifaceted concept of 'access'. Most discussions concentrate on lack of IT equipment and network connectivity. Yet Van Dijk (2006) suggests that there are in fact three additional barriers to access, all of which are relevant to Traveller families. 
These include a lack of elementary digital experience, a lack of digital skills and a lack of significant user opportunities.

ELAMP addressed all of the aforementioned barriers and along with other governmental initiatives, resulted in over 2,000 Traveller families accessing laptops with Internet access. ELAMP took a very practical approach in defining and targeting digital inclusion by proving IT equipment along with sensitive and appropriate support to re-engage those disaffected from school education. ELAMP enabled Traveller families to be more digitally and consequently socially included through having access to IT and Internet.

Research evaluations can ignore the difficulties projects faced. This article will now discuss the challenges ELAMP experienced, including the need for specialised teacher support, geographical locations, lack of computer literacy, social networking and safeguarding to provide a rounded picture of ELAMP successes and struggles with project implementation.

\section{The challenges for ELAMP and digital inclusion}

\section{Educational support}

In terms of digital access and literacy, ELAMP provided schools and TES staff with a well-structured IT initiative through which they could reach out and work with Traveller families to enhance their experiences of education. Although the Strand B was originally designed to be stand-alone distance-learning programme, early experiences indicated that learners needed regular and on-going face-to-face support. Marks (2010) noted that distance learning should not be considered as a comprehensive solution for all mobile or all Traveller families.

ELAMP progress was heavily reliant upon appropriate, sensitive and flexible professional support by those who had a good understanding and experience of working with Traveller communities. Consequently ELAMP only worked well with committed families and schools and the continuing work of TES. ELAMP project evaluation confirmed that ELAMP's success was heavily reliant upon TES as specialists in the field of Traveller education to bridge relations between teachers in schools and families themselves. TES were also there to ensure that all families, including non-mobile families, who were new to using laptops and the Internet, were supported in their use of IT. Thus staff encouraged computer literacy and education.

\section{Geographical location}

The location of mobile and more settled Traveller families often meant that group work was not possible. Moreover, access to the Internet could be very weak. Downloading documents or even sending emails could be an extremely frustrating process. As technology advanced ELAMP replaced data cards with dongles, which did speed up connectivity, nevertheless many could not rely or depend on it because of localised connection problems and communication black spots. Within the Strand $\mathrm{B}$ part of ELAMP an off-line CD was produced containing all learning materials to ensure that educational progress was not hampered through poor Internet facilities. 


\section{K. D’Arcy}

\section{Lack of computer and literacy}

The IT skills of learners and their families were often limited, especially where children had perhaps not been attending school for some time. Tutors needed to support learners and their parents with the very basics of computing before they could start the project. Basic IT training as well as on-going support was vital for progression. On-going IT support was particular important when technology failed or laptops became very dated, or got broken or damaged in transit. TES and school teachers' time spent on supporting IT was often equivalent to the hours spent on teaching and tutoring or marking work. The financial implications of this support and the costs of insuring and maintaining equipment were therefore significant.

\section{Social networking and safeguarding}

Social networking was important to children and young people but also their families. Many parents used the Internet to access services and make contact with long lost family members or those who they simply did not see due to being geographically removed. Many parents wanted to research their family histories and businesses on-line. Yet many adults and children were not confident in using IT and this provided a safeguarding challenge. ELAMP considered the protection of children and their families in safe use of the Internet as essential. Training events with staff and families took place frequently and a number of recommended resources ${ }^{7}$ were distributed and used with Traveller families.

As technologies developed project managers decided that it would be safer to block access to certain sites for young children. However this had a generally negative effect on older, secondary-aged participants' engagement with the technology, as they wanted to use the Internet for social networking as well as their learning. As laptops were wireless some young people went and used open access areas such as libraries or McDonald's instead. There was therefore a real challenge between protecting children and young people and enabling their digital inclusion.

\section{Critical questions: future learning and digital developments}

ELAMP focussed upon improving the learning experiences and achievements of Travellers in education. ELAMP also provided families with IT equipment and Internet connectivity, which reduced their digital exclusion and in doing so also reduced their social exclusion. ELAMP was a tool that produced and provided relevant learning content, which in turn compelled its use. In this way ELAMP facilitated agency and choice and addressed many of the traditional barriers to educational and digital inclusion. ELAMP equalised differences between learners in and out of school, thereby reducing divisions in education by providing access to IT equipment and the Internet. Indeed the ELAMP initiative paved the way for the Home Access project, which was a government-funded scheme to provide school children in low-income families with computers and Internet access to support their learning. Still, many of the lessons learnt as part of ELAMP were not considered in the roll out of the Home Access programme in 2010 and this will be considered briefly next as it has implications for future learning and digital developments. 


\section{Home Access}

The Home Access initiative was a notable financial investment in advancing the provision of computer equipment for low-income families. The vision for Home Access was "to ensure that all pupils aged 5-19 in state maintained education in England have the opportunity to have access to computers and Internet connectivity for education ... at home" (DfE 2011, p. 7).

The scheme acknowledged the impact of not having computer access in the home as children's learning in school and social inclusion is reduced. The programme adopted a 'consumer' model to address this problem; individual families who met specific criteria ${ }^{8}$ could apply for a home-access grant to fund a computer/laptop with connectivity in the home. Although the Department for Education (DfE 2011) suggest many Local Authorities welcomed the model as it reduced the administrative burden on them, the system caused several problems for Traveller families. Indeed personal experience of working in a Traveller Education Service indicated that there were two key challenges regarding initial and on-going support that prevented equipment usage and benefits.

First, the application was complex and lengthy - in many cases families relied heavily upon professional support to complete their application. Second, there was limited IT support for families when equipment arrived, and many received no basic set-up instructions or manual to help get started. Although IT support was offered on-line and via the phone, the latter had to be paid for and many individuals did not feel confident to use these support systems. In the longer term, laptops rely on regular IT updates and families were not always aware of how to do this. In many cases as TES declined and technical issues emerged, laptops were simply left unused. Warschauer (2003) suggested that the worst digital failures occur when a narrow focus on provision of equipment aims to address complex social problems. Indeed, research has long indicated that the digital divide is about more than IT equipment alone (Van Dijk 2006), observations of Home Access project confirmed these findings. Digital inclusion for Traveller communities requires on-going implementation and a commitment that is not just purely focussed upon the provision of computer equipment and Internet connectivity alone.

The DfE's own evaluation also highlighted that 'leakage' was high - most (55\%) of beneficiary households already had both a computer and Internet at home before they received the Home Access grant (2011, p. 6). Thus, in many senses this project was a wasted opportunity for those most digitally excluded. Furthermore, Home Access was a very short initiative and although Traveller families may well have become more digitally included during ELAMP and Home Access, they have now been excluded again. Indeed, now that both ELAMP and Home Access projects have ended there do need to be critical questions raised about the notable lack of developments regarding Travellers' digital inclusion today. The next section will now consider what is holding further implementation and progress of this work back.

\section{Conclusion}

Despite their challenges and limitations, both ELAMP and the Home Access programme focussed upon education and IT progression together. What we have learnt is that this can be effective in reducing educational and digital exclusion. There are clear benefits in adopting policy initiatives that address learning and IT together. 


\section{K. D'Arcy}

ELAMP and IT projects that happened previously demonstrate that it is useful to draw upon a range of pragmatic IT activities which make IT relevant and compel users to engage. Projects should consider users' everyday needs and match these with individual's interests and aspirations. Interdisciplinary approaches are important and a range of stakeholders should be included to maximise effect. Participants might include teachers, schools, specialist support services, libraries, technologists and families themselves to play an active part in the development of future projects and initiatives. Ethical considerations are also paramount. Internet safety and protection needs to be balanced with the importance of social networking.

There must also be recognition of the fact that Traveller communities experience a wide range of compounded disadvantages in access to education and IT. In a time where council budgets are being slashed and TES with their specialised support for Traveller communities are diminishing, questions need to be asked about the social (including the digital) inclusion of the most vulnerable. Raising educational underachievement and reducing the digital divide should be on-going priorities for Traveller communities. However, when considering future practice, we need to be realistic and acknowledge that educational and digital inclusion requires more than IT equipment alone, it requires on-going commitment and resources. These resources include professional support that is expensive initially; however good practice in the field suggests that well planned projects can empower community members themselves to help sustain and develop the work in the longer term, thereby reducing costs.

Projects such as ELAMP provide a useful case-study of what works to bridge the educational and digital gap for marginalised learners. What is currently lacking is specific funding and focus to continue and develop this work. Consequently many Traveller families remain socially and digitally excluded. Future initiatives need to recall that many individuals are still excluded from education and the digital world and the barriers that prevent their inclusion, including geography, technology, skills, equipment, on-going support and personal ownership for learning. Addressing such exclusion requires on-going implementation and a commitment. There is a need for a renewed, joined-up commitment to reduce the social, education and digital divide for Traveller communities. We do have a basic understanding of what works - what is now needed is a long-term vision and the necessary resources to support such a vision.

\section{Notes}

1. Please visit the National Association of Teachers and Travellers + other professionals $(\mathrm{NATT}+)$ on-line for all reports on ELAMP.

2. The first of EFECOT's projects.

3. A programme that intended to promote access to computers and the Internet in the homes of school-aged children by providing funding to low-income families.

4. The dongle is a USB stick enabling those without phone lines and broadband to access the Internet. Inside the dongle was a SIM card. The dongle used mobile technology to activate Internet access.

5. The name Chanel is a pseudonym to protect the identity of this young Traveller.

6. Unpublished data collected as part of the ELAMP evaluation.

7. For example, the 'Know-it-all' free CD produced by ChildNet.

8. To be eligible families had to have a child attending school full-time (in Years 3-9) and be in receipt of state benefits. 


\section{References}

Asdan (2011) Wider Key Skills Qualifications, [online] Available at: www.asdan.org.uk/ Qualifications/Key-Skills

Bernstein, B. (1974) Class, Codes and Control, Routledge \& Kegan Paul, London.

Casacuberta, D. (2007) 'Digital inclusion: best practice from eLearning', eLearning Papers, no 6, November 2007.

D'Arcy, K. \& Marks, K. (2008) 'Disengaged Traveller children and ICT: the ELAMP project', Race, Equality Teaching, vol. 27, no. 1, pp. 27-31.

Derrington, C. \& Kendall, C. (2004) Gypsy Traveller Student in Secondary Schools, Trentham Books, Stoke-on-Trent.

Digital Inclusion Team (2007) The Digital Inclusion Landscape in England Delivering Social Impact through Information and Communication Technology, [online] Available at: http:// www.epracitce.eu/files/media/media1881.pdf

Doherty, M. (2011) Cuts to Traveller Education Services, [online] Available at: http://www. acert.org.uk/

Equality and Human Rights Commission (2010) How Fair Is Britain? Equality, Human Rights and Good Relations in 2010. The First Triennial Review, [online] Available at: http://www. equalityhumanrights.com/key-projects/how-fair-is-britain/

Futurelab (2007) Opening Education, beyond the Digital Divide, Rethinking Digital Inclusion for the 21st Century, [online] Available at: http://archive.futurelab.org.uk/resources/documents/ opening_education/Digital_Divide.pdf

Gewirtz, S. \& Cribb, A. (2009) Understanding Education. A Sociological Perspective, Polity Press, Cambridge.

Jordan, E. (2001) 'Exclusion of Travellers in state schools', Educational Research, vol. 43, no. 2, pp. 117-132.

Lloyd, G. \& McClusky, G. (2008) "Education and Gypsy Travellers: contradictions and significant silences", International Journal of Inclusive Education, vol. 12, no. 4, pp. $331-345$.

Marks, K. (2003) 'EFECOT supporting the Traveller tradition', in The Open Classroom: Distance Learning in Schools (Open \& Distance Learning), ed. J. Bradley, Routledge, London.

Marks, K. (2005) The E-Learning and Mobility Project (E-LAMP2), Final report (with supplementary information from a parallel project), The Department of Educational Studies, The University of Sheffield, UK.

Marks, K. (2010) ELAMP Strand A: Final Report and Impact Study (2009-10), The Department of Educational Studies, The University of Sheffield, UK.

Monk, D. (2004) 'Problematising home-education: challenging "parental rights" and "socialism"”, Legal Studies, vol. 24, no. 4, pp. 568-598.

Office for Standards in Education (2003) Provision and Support for Traveller Pupils, REF: HMI 455, November 2003, OFSTED, UK.

Raey, D. (2010) 'The hereditary curse of the education system? The case of class in English education', EdD presentation paper, The University of Sheffield, UK.

Strover, S. (2003) 'Remapping the digital divide', The Information Society: An International Journal, vol. 19, no. 4, pp. 275-277.

The Department for Children, Schools and Families (DCSF) (2008) Attendance Advice; Gypsy, Roma and Traveller Children - the National Strategies, DCSF, UK.

The Department for Education (DfE) (2011) Evaluation of the Home Access Programme, The Final Report, Research Report DFE-RR132SQW (in partnership with Ipsos Mori and London Knowledge Lab), DfE, UK.

Van Dijk, J. (2006) The Network Society, 2nd edn, Sage Publications, London.

Warschauer, M. (2003) 'De-mystifying the digital device', Scientific American, vol. 289, no. 2, pp. $42-47$.

Wilkin, A., Derrington, C., \& Foster, B. (2009) Improving the Outcomes for Gypsy, Roma and Traveller pupils, Literature Review, Research Report DCSF-RRO77, DCSF, UK.

Wilkin, A., et al. (2006-2010) Improving the Outcomes for Gypsy, Roma and Traveller Pupils: Final Report, Research Report DFE-RR043, Department for Education, UK.

Willers, M. (2012) 'Tackling inequalities suffered by Gypsies and Travellers', TAT news, Newsletter Spring 2012, Travellers Advice Team. 